\title{
Corrigendum: Mapping autism risk loci using genetic linkage and chromo- somal rearrangements
}

The Autism Genome Project Consortium

Nat. Genet. 39, 319-328 (2007); published online 18 February; corrected after print 26 September 2007

In the version of this article originally published, Kacie J. Meyer (University of Iowa, Iowa City) was inadvertently omitted from the list of authors, and the names of three authors (Frederieke Koop, Marjolein Langemeijer and Channa Hijmans) were misspelled. Also, the third sentence of the abstract incorrectly stated that 1,168 families were analyzed. The correct number is 1,181 families. Finally, the last paragraph of the Discussion mistakenly identified one of the linkage regions as 11q13-12. This should read 11p13-12. These errors have been corrected in the HTML and PDF versions of the article.

\section{Corrigendum: Nuclear reprogramming of cloned embryos and its implica-} tions for therapeutic cloning

Xiangzhong Yang, Sadie L Smith, X Cindy Tian, Harris A Lewin, Jean-Paul Renard \& Teruhiko Wakayama

Nat. Genet. 39, 295-302 (2007); published online 26 February; corrected after print 26 September 2007

In the version of this article initially published, the legend for Figure 1 is inaccurate. The original legend for Figure 1c failed to note that the cells derived from cattle embryos were embryonic stem cell (ESC)-like or trophectoderm cell colonies. The full legend for Figure 1c should read

"Therapeutic cloning: percentage ESC line derivation (mice) or ESC-like or trophectoderm cell colony formation (cattle) from embryos derived from both IVF and nuclear transfer." This error has been corrected in the HTML and PDF versions of the article.

\section{Corrigendum: Variation in FTO contributes to childhood obesity and severe adult obesity}

Christian Dina, David Meyre, Sophie Gallina, Emmanuelle Durand, Antje Körner, Peter Jacobson, Lena M S Carlsson, Wieland Kiess, Vincent Vatin, Cecile Lecoeur, Jérome Delplanque, Emmanuel Vaillant, François Pattou, Juan Ruiz, Jacques Weill, Claire Levy-Marchal, Fritz Horber, Natascha Potoczna, Serge Hercberg, Catherine Le Stunff, Pierre Bougnères, Peter Kovacs, Michel Marre, Beverley Balkau, Stéphane Cauchi, Jean-Claude Chèvre \& Philippe Froguel

Nat. Genet. 39, 724-726 (2007); published online 13 May; corrected after print 26 September 2007

In the version of this article initially published, the authors failed to acknowledge that recruitment of obese cases was supported by both AssistancePublique Hôpitaux de Paris and Centre National de la Recherche Scientifique. This error has been corrected in the PDF version of the article. 